\title{
O padrão discursivo barretiano da obra Clara dos Anjos e a possibilidade dessa releitura contemporânea
}

\section{The discursive standard of barretiano's work Clara dos Anjos and the possibility that contemporary rereading}

Adriana dos Reis Silva

Centro Universitário de Belo Horizonte (Unibh), Belo Horizonte, Minas Gerais, Brasil. adrianasier@yahoo.com.br

Resumo: O presente estudo objetiva mostrar o padrão discursivo racial na produção da obra Clara dos Anjos (1922) de Lima Barreto em contraposição a essa releitura a telenovela Fera ferida (1993), de Aguinaldo Silva, Ricardo Linhares e Ana Maria Moretzsohn. Para constituir o aporte teórico estabelecido nesse trabalho, utilizamos a noção de formação discursiva segundo Michel Pêcheux (1997), buscando apreender, como a macroesturação enunciativa dos objetos Clara dos Anjos e Fera ferida se articulam através da perspectiva do dizer racial brasileiro. Parece-nos, que nesse sentido a filiação discursiva dos autores têm a capacidade de reproduzir a veleidade racial brasileira, legitimando o mito da democracia racial e o posicionamento imposto pela classe dirigente, que preza o domínio de vida capitalista. Contudo, a obra de Barreto ressignifica a óptica racial por meio da criação de "uma literatura social politicamente militante, voltada para a urgência do cotidiano em mudança e ao mesmo tempo inspirada na redenção do homem e na defesa do trabalhador oprimido pelas distorções sociais". (PRADO, 1980, p. 13). De forma divergente, a narrativa Fera ferida mostrará, em sua trama, a desconstrução dos discursos produzidos sobre o negro, perspectiva que distorce a racialidade e, consequentemente, demanda uma nova ordem, como a criação de leis que se interpõem de forma a rever a questão racial. 
Palavras-chave: formação discursiva; racialidade; discurso.

Abstract: This study aims to show the racial pattern in the discursive production of Clara dos Anjos (1922), work of Lima Barreto in contrast to that rereading the soap opera Fera Ferida (1993), written by Aguinaldo Silva, Ricardo Linhares and Ana Maria Moretzsohn. Constituting the theoretical framework established in this work, we use the notion of discursive formation according to Michel Pêcheux (1997), seeking to understand, as the macrostructure enunciation of objects Clara dos Anjos and Fera Ferida articulate through the perspective of the Brazilian racial say. It seems to me that, in that sense the discursive affiliation of authors has the ability to play the Brazilian racial whim, legitimizing myth of racial democracy and the position imposed by the ruling class, which values the capitalist life domain. However, the work of Barreto resignifies racial optical through the creation of "a politically militant social literature, focused on the urgency of change in everyday and at the same time inspired by the redemption of man and the defense of the oppressed worker by social distortions." (PRADO, 1980, p. 13). In different ways, the Fera Ferida narrative shows in its plot, the deconstruction of discourses produced on black, perspective that distorts raciality and therefore demand a new order, such as the creation of laws that stand in order to review the racial issue.

Keywords: discursive formation; raciality; speech.

Recebido em 22 de setembro de 2015. Aprovado em 04 de novembro de 2015.

\section{Introdução}

Neste trabalho procura-se observar o padrão discursivo racial na produção da obra Clara dos Anjos (1922) de Lima Barreto colocada em contraposição com uma releitura feita por Aguinaldo Silva, Ricardo Linhares e Ana Maria Moretzsohn, que resultou na telenovela Fera ferida (1993), uma realização da Rede Globo de Televisão.

A escritura de Clara dos Anjos de Barreto, a nosso ver, erige-se como uma lâmina cortante, subverte o beletrismo de sua época e deixa esvair a voz dos amargurados. Para tanto, observe-se como o autor, por 
uma via engenhosa, mostra um momento de devaneio e introspecção de sua personagem Clara dos Anjos:

Clara contemplava o céu negro, picado de estrelas, que palpitavam. A treva não era total, por causa da poeira luminosa que peneirava das alturas. (...) só distinguia o Cruzeiro do Sul. Correu com o pensamento errante toda a extensão da parte do céu que avistava. Voltou ao Cruzeiro, em cujas proximidades, pela primeira vez, reparou que havia uma mancha negra, de um negro profundo e homogêneo de carvão vegetal. Perguntou de si para si:

- Então, no céu, também se encontram manchas?

Essa descoberta, ela a combinou com o transe por que passara. Não lhe tardaram a vir lágrimas; e, suspirando, pensou de si para si:

-Que será de mim, meu Deus?

Se "ele" [Cassi Jones] a abandonasse, ela estava completamente desmoralizada, sem esperança de remissão, de salvação, de resgate... Moça, na flor da idade, cheia de vida, seria como aquele céu belo, sedutoramente iluminado pelas estrelas, que também tinha ao lado de tanta beleza, de tanta luz, de não sabia que sublime poesia, aquela mancha negra como carvão. Cassi a teria de fato abandonado? Ela não podia crer, embora há quase dez dias não a viesse ver. Se ele a abandonasse - o que seria dela? Veio-lhe então perguntar a si mesma como se entregou. Como foi que ela se deixou perder definitivamente? (BARRETO, 1998, p. 117).

Esse fragmento textual alude à condição da mulata Clara dos Anjos, personagem da narrativa barretiana publicada em romance em 1948, que apresenta como título, o mesmo nome da moça, Clara dos Anjos. A jovem protagoniza uma história de desamparo, pobreza e preconceito, como veremos a seguir. A partir da metáfora da mancha acima transcrita, vem à tona a percepção da personagem Clara acerca dos acontecimentos que a rodeiam. Aqui ela parece se encontrar e/ou começar a ter noção de quem é. Ao constatar que "até o céu tinha mancha" - a mácula negra - a personagem reflete sobre o que esperar de sua situação, já que sua cor representava a ignomínia social. Ela percebe que o estigma 
da cor negra permeia outros âmbitos da natureza, e não só sua condição. Mais do que isso, ela se dá conta de que, na sociedade em que vive, a infâmia se abate sobre a imagem do negro. ${ }^{1}$

Clara consegue, por meio dessa percepção, anunciar seu destino: estaria fadada à imobilidade social e econômica. O sentimento de isolamento e de abandono atordoa o mundo de Clara - "Que será de mim, meu Deus?" (BARRETO, 1998, p. 117).

É por meio da consciência de raça apresentada pela personagem Clara dos Anjos, a qual sangra em veias abertas o seu destino enquanto mulata, que gostaríamos de contrapor tal construção discursiva com aquela realizada pela contemporaneidade da telenovela Fera ferida, de Aguinaldo Silva, Ricardo Linhares e Ana Maria Moretzsohn, realizada pela Rede Globo de Televisão em 1993. A novela se passa na cidade ficcional de Tubiacanga, tendo como protagonista Raimundo Flamel ou Feliciano Júnior (Edson Celulari), que volta a essa cidade para vingar a morte de seus pais.

Nessa narrativa encontramo-nos, também, com personagens presentes em contos de Lima Barreto, como: "Nova Califórnia", com os personagens Flamel, Major Bentes etc.; "O homem que sabia Javanês" (1911), com o personagem Castelo (aquele que dizia saber javanês), além, de "Clara dos Anjos", com os personagens Engrácia, Clara, Joaquim, D. Margarida, Cassi Jones, Salustiana, entre outros. Até o próprio Lima Barreto é reconstituído em Fera ferida através do personagem poeta Afonso Henriques de Lima Barreto, interpretado pelo ator Otávio Augusto. Além disso, a novela faz outra menção a Lima Barreto ao mostrar sua foto com a faixa presidencial dentro do gabinete da cidade ficcional de Tubiacanga.

A novela, assim, projeta várias tramas paralelas, como traição, corrupção, racismo etc, sendo que nosso enfoque, a princípio, se volta para o núcleo vivenciado pela personagem Clara dos Anjos e as condições racializantes estabelecidas naquele contexto.

Para constituir sua obra, pressupomos que o autor Lima Barreto contou com certos saberes partilhados, como a questão racial no âmbito social. Nesse ritual linguageiro, Barreto deixa subentendidos, em

\footnotetext{
${ }^{1}$ Essa inferência se torna possível porque, "existe um consenso intersubjetivo pelo qual o idealismo promove a compreensão do indivíduo a partir de seu pensamento". (PÊCHEUX, 1997, p. 162).
} 
sua enunciação, aspectos marcantes que projetam, possivelmente, as vivências singulares, de outrora. Vejamos:

$>$ inconformidade: "O espectro da escravidão, com todo o seu cotejo de infâmias, causa-lhe secretas revoltas." (BARRETO, 1998, p. 36);

$>$ indignação: "O povo é avesso a guardar os nomes dos autores, mesmo os dos romances, folhetins que custam dias e dias de leitura. A obra é tudo para o pequeno povo; o autor nada." (BARRETO, 1998, p. 51);

> pobreza: "Toda essa população, pobríssima, vive sob a ameaça constante da varíola e, quando ela dá para aquelas bandas, é um verdadeiro flagelo." (BARRETO, 1998, p. 72);

$>$ denúncia: "Mais ou menos é assim o subúrbio, na sua pobreza e no abandono em que os poderes públicos o deixam. (...) O subúrbio é o refúgio dos infelizes. Os que perderam o emprego, as fortunas; os que faliram nos negócios, enfim, todos os que perderam a sua situação normal vão se aninhar lá; e todos os dias, bem cedo, lá descem à procura de amigos fiéis que os amparem, que lhes dêem alguma coisa, para o sustento seu e dos filhos.” (BARRETO, 1998, p. 74);

dentre outros.

Barreto, enquanto escritor, idealiza um leitor que lhe seja contemporâneo, que irá interagir com sua escritura, de função social, já que "nunca, um minuto só da sua vida, pôs a sua pena a serviço de nenhuma causa iníqua”. (LINS, 1976, p. 175). Já o leitor empírico extemporâneo deve reconhecer que esse autor escreveu em determinada época (século passado), a qual contextualiza certos aspectos próprios daquele tempo, como a escravidão, as inovações republicanas etc. Ao esse leitor real, portanto, cabe realizar a interpretação do texto.

No âmbito televisivo brasileiro Aguinaldo Silva, por sua vez, é conhecido como "Senhor das Oito", considerando o número de telenovelas que ele já escreveu para esse horário. Mas esse autor, na

${ }^{2}$ Cfe. Portal Globo. Disponível em: <http://ego.globo.com/famosos/tudo-sobre/ aguinaldo-silva.html> Acesso em: 20 jan. 2014. 
produção de Fera ferida, teve a colaboração de mais dois sujeitos comunicantes: Ana Maria Moretszohn e Ricardo Linhares parceiros que em conjunto elaboraram a trama televisiva.

É interessante ressalvar que essa escritura se faz sob um gênero inscrito em um veículo comunicacional que, em prática, atua na produção das relações sociais, as quais se estabelecem por meio da articulação das formas de conteúdos e expressões, permeando o imaginário dos cidadãos brasileiros pela mídia televisiva. Os autores de Fera ferida assumem a função de escritores telenovelísticos e, dessa forma, assumem a legitimidade sobre a escrita desse gênero, tendo, é claro, a cooperação de uma série de parceiros e a maior parte deles com um único propósito: o entretenimento. Diante disso, os efeitos de sentido possíveis são muitos, levando em consideração que, nessa leitura telenovelística, múltiplos contratos comunicacionais podem surgir, tanto pela trama central da novela quanto pelas tramas paralelas, revestindo o espectador do poder do ato interpretativo, pois na medida em que decorre a trama ele pode intervir, dando sua opinião, por exemplo, a partir do IBOPE - que é o Instituto Brasileiro de Opinião e Estatística, um medidor da audiência televisiva.

\section{A Formação Discursiva em Barreto versus a contemporanei- dade de Fera Ferida}

Para constituir o aporte teórico estabelecido nesse estudo, utilizaremos a noção de formação discursiva segundo Michel Pêcheux (1997).

A base do pensamento de Pêcheux se constitui sob a interpelação do sujeito pela ideologia. As formações discursivas nesse contexto se compõem pelos diversos interdiscursos e, assim, possuem ideologias distintas no seu interior.

De acordo com esse autor, a ideologia indica, através do "hábito" e do "uso", "o que é" e "o que deve ser" e isso, em alguns casos, por intermédio de desvios linguisticamente assinalados em meio do preceito e da constatação, funcionando como dispositivo de "retomada do jogo". As evidências pelas quais "todo mundo sabe" o que é, por exemplo, um soldado, um operário, uma fábrica, uma greve, etc. são geradas pela ideologia. Essas certezas manifestas fazem que um enunciado/palavra diga o que realmente deseja dizer, sendo mascarado sob a "opacidade da linguagem", isto é, a materialidade do sentido contido nos léxicos e enunciados. (PECHEUX, 1997, p. 159). 
Nesse sentido, o autor considera que o caráter material do sentido, mascarado por sua evidência transparente para o sujeito, consiste na sua dependência constitutiva daquilo que chamamos "o todo complexo das formações ideológicas.” (PECHEUX, 1997, p. 160). Diante dessa afirmação o autor busca especificar essa espécie de subordinação do sentido através do seguinte princípio: o sentido de uma palavra, expressão, proposição etc. não existe por si, isto é, em sua correspondência com a literalidade significante na qual é introduzido, sendo, então, estabelecido pelas posições ideológicas inscritas no jogo do processo social e histórico com os quais essas palavras, expressões, proposições etc. são confrontadas.

Reconhecemos, então, uma formação discursiva, segundo Pêcheux, a partir de sua constituição que se estabelece por

aquilo que numa formação ideológica dada, isto é, a partir de uma posição dada numa conjuntura dada, determinada pelo estado da luta de classes, determina o que pode e deve ser dito (articulado sob a forma de uma arenga, de um sermão, de um panfleto, de uma exposição, de um programa, etc.). (PECHEUX, 1997, p. 160).

As Formações Discursivas - doravante denominadas FD - são, nessas circunstâncias, projeções, na linguagem, de certas formações ideológicas vigentes. Logo, o sentido de um estado de coisas só é adquirido a partir do posicionamento daqueles que o empregam, inscritos sob uma dada ideologia.

Para Pêcheux (1997), qualquer formação discursiva dissimula, pela diafaneidade de seu sentido, sua dependência ao "todo complexo com dominante" das formações discursivas, enredado no complexo das formações ideológicas. A esse "todo complexo com dominante" das formações discursivas atribui-se o nome de interdiscurso:

Diremos, nessas contradições, que é próprio de toda formação discursiva é dissimular, na transparência do sentido que nela se forma, a objetividade material contraditória do interdiscurso, que determina essa formação discursiva como tal, objetividade material essa que reside no fato de que "algo fala" (ça parle) sempre "antes, em outro lugar e independentemente", isto é, sob a dominação do complexo das formações ideológicas. (PECHEUX, 1997, p. 162 - destaques do autor). 
Pode-se compreender essa passagem como algo relativo a uma memória discursiva constituída por um esquecimento determinante, com base no princípio de que todo discurso se manifesta na relação com a sua alteridade/exterioridade ou, ainda, numa interação constitutiva com outros discursos.

O interdiscurso assinala o espaço discursivo e ideológico no qual se desenvolvem as formações discursivas sob as relações de subordinação, dominação e contradições existentes no âmbito enunciativo.

A partir dessas considerações, Pêcheux (1997) aponta dois tipos de discrepâncias para a questão em pauta: o efeito de encadeamento do pré-construído (ilusão da existência de uma realidade dada como tal e representável pelo discurso) e a articulação (ilusão da existência de uma relação explicativa entre os sentidos que funcionaria como processo de sustentação do discurso). Essas discrepâncias são determinadas na própria estrutura do interdiscurso.

A noção de formação discursiva, desse modo, é concebida, pelo referido autor, em termos de regularidades distintivas de posições sociais determinadas em função das lutas ideológicas constitutivas de uma conjuntura histórica e política.

Orlandi (2010) afirma que pelo funcionamento das formações discursivas e do interdiscurso, podemos apreender os mecanismos ideológicos para a constituição do sujeito e do sentido. A formação discursiva, enquanto conceito torna possível que sujeitos empíricos apreendam os sentido de certas palavras, expressões etc. em um determinado período histórico.

Uma FD é, portanto, heterogênea a ela própria: o fechamento de uma FD é fundamentalmente instável, ela não consiste em um limite traçado de forma definitiva, separando um exterior e um interior, mas se inscreve entre diversas FDs como uma fronteira que se desloca em função dos embates da luta ideológica. (COURTINE \& MARANDIN, 1981, p. 41).

Assim, uma formação discursiva pressupõe uma unidade heterogênea, indispensável àquilo que deve e pode ser dito em um dado momento da vida social humana.

Valemo-nos, nessa pesquisa, do conceito de FD, buscando apreender, como a macroesturação enunciativa dos objetos Clara dos 
Anjos e Fera ferida se articulam através da perspectiva do dizer racial brasileiro. Contudo, trataremos ainda certas cenas das narrativas em questão, a título de esclarecimento, ou seja, veremos alguns pontos da microestruração enunciativa que nos parecem relevantes para a $o$ entendimento das FD's que perpassam os objetos como um todo.

Conduziremos a investigação a partir do lugar social/empírico que cada um dos sujeitos comunicantes assume no discurso racializante brasileiro. Iniciamos com Lima Barreto para, em seguida, passarmos ao posicionamento ideológico televisivo e a autoria telenovelística.

Para discorrer sobre o lugar social em que Lima Barreto se inscreve e as relações de classe presentes no contexto por ele vivido, é importante entendermos que as relações sociais se baseiam em determinados preceitos hierárquicos (status, situação econômica, cultural etc.), e o Brasil, no que diz respeito às hierarquias, revela algumas combinações que estão intimamente ligadas ao processo de formação das diferenças sociais brasileiras como a raça, classe ou a cor do indivíduo (lembremo-nos que Barreto é um mulato).

O discurso racial brasileiro possui, em sua base, um pilar escravagista, sustentado pelo pensamento eugênico e eurocêntrico. Esse contexto se apropriou de uma de configuração liberal-escravista, instituindo uma ideologia que perdurou anos, que só começou a ser contestada com a escassez da mão de obra negra, após extinção do tráfico negreiro. (BOSI, 1995).

A ascensão do negro/mulato/afrodescendente ocorreu nessa 'nação' sob um processo de concessão de regalias ao sujeito branco, deixando o negro à margem, - a civilidade brasileira em relação aos homens de cor se fez sob os segmentos privilegiados da raça dominante. (FERNANDES, 1972).

(...) as posições desvantajosas dos estoques negro e mulato na estrutura socioeconômica condiciona formas de participação cultural e de integração ao sistema de classes que favorecem a sua perpetuação crônica naquelas posições, em vez de estimularem a ruptura com o passado e as sua superação. (FERNANDES, 1972, p. 49).

Os padrões deformadores da condição negra no Brasil perpetuam ainda no contexto brasileiro. A herança escravagista pode ser observada por meio de formas discriminatórias utilizadas discursivamente para lidar 
com o sujeito de cor. Esses indivíduos formam "uma espécie de escória da grande cidade" e se veem condenados a uma miséria social que os degrada terrivelmente. (FERNANDES, 1972, p. 42).

Lima Barreto nasceu em 1881 e cresceu sob panorama político e social marcado pela Abolição da Escravatura (1888) e a Proclamação da República (1889). Presenciou a sucessão de vários presidentes, como Afonso Pena (1909), Nilo Peçanha (1909-1910), entre outros. Ainda, assistiu a um período de crise no Brasil, com desempregos, reivindicações políticas, e tudo isso, concomitante a primeira Guerra Mundial, o que tornou a situação brasileira ainda pior.

Esse é o cenário no qual o Barreto se faz escritor, sua obra se constitui em um período evidenciado por momentos de saudosismos, de reforma, mas, apresentando, também, a irreverência das vanguardas, da psicanálise, da relatividade de Einstein, da Revolução Russa, da anarquia espanhola e dos sindicatos fascistas. (BOSI, 1970, p. 342-343). Enquanto jovem, Barreto, estudou na Politécnica do Rio de Janeiro, ali sofreu preconceitos de seus colegas, era o estranho no meio de jovens abastados brancos. Já adulto, de forma muito comum, chamavam-no de negro, às vezes era tomado como bandido. Barreto misturava-se com todo o tipo de pessoas, prostitutas, viciados etc. (PRADO, 1999). O escritor era consciente da situação brasileira, ele a vivia e combatia a desigualdade do país através de sua escritura, tornando-se assim um porta-voz dos "infelizes".

Encontraremos, em suas páginas íntimas, expressões de desalento, mas não de autocomiseração. Mesmo as alusões constantes ao problema da cor ou à adoração nacional pelos doutores, embora ligadas a experiências pessoais, voltamse para fora, para a sociedade que conhece e sobre a qual testemunha. (LINS, 1976, p. 24).

Lima Barreto é um indivíduo descontente com a sociedade, a literatura que ele cria fornece pistas para tal apreensão. Vejamos, por exemplo: "a vida cara, enquanto os salários eram mais ou menos os mesmos anteriores. $\mathrm{O}$ descontentamento se fez e os pobres começaram a ver que, enquanto eles ficavam mais pobres, os ricos ficavam mais ricos" (BARRETO, 1956, p. 54). O autor [,] em sua incursão literária busca promover reflexões sócio-raciais e políticas. Ele ironiza e escarnece de uma sociedade nada convencional e democrática, mas, a elite de sua época não o perdoa por tal fato. 
As classes dominantes (e, com elas, amplos setores das classes dominadas, que refletem em grande parte a visão conservadora) são particularmente sensíveis no Brasil aos que as renegam de maneira ostensiva. Pareceu-me sofrer Lima Barreto, e creio não enganar-me, o efeito de uma ação difusa, um processo disfarçado, surdo, de sonegação (muito semelhante, por sinal, ao que entre nós marginaliza o negro). Acresce que os povos mostram-se sensíveis às idealizações. E Lima Barreto é talvez o autor brasileiro que nos viu até hoje com maior verdade e lucidez. (LINS, 1976, p. 12).

Nesse sentido, Barreto toma a literatura não como expressão, mas, principalmente, como "comunicação militante", palavra empregada pelo autor que "se engaja, tão ostensivamente quanto possível, com suas palavras e o que elas transportam, a mover, demover, comover, remover e promover." (LINS, 1976, p. 18). O escritor através de sua escrita confronta a sociedade brasileira e é ignorado por ela.

O âmbito social e histórico vivido por Barreto, como vemos, advém do domínio dos grandes latifúndios - os senhores de escravo. A formação social, nesse contexto, presentifica um processo de produção no qual as forças produtivas são movidas pelas leis escravagistas. Sob esse aspecto Althusser (1983, p. 10), considera que uma formação social "releva de um modo de produção dominante, podemos dizer que o processo de produção põe em movimento forças produtivas existentes em (dans et sous) relações de produção definidas". Logo, a relação de produção subsistente na nação brasileira defendia a coisificação do negro, determinante para um ideário racista.

Os pretos e descendentes de pretos, esses continuavam relegados, ao menos em certos textos oficiais, a trabalhos de baixa reputação, os negro jobs, que tanto degradam o indivíduo que os exerce, como sua geração. Assim é que, em portaria de 6 de agosto de 1771, o vice-rei do Brasil mandou dar baixa do posto de capitão-mor a um índio, porque "se mostrara de tão baixos sentimentos que casou com uma preta, manchando o seu sangue com esta aliança, e tornando-se assim indigno de exercer o referido posto". (HOLANDA, 1995, p. 56 - destaques do autor). 
Nota-se, desde logo, que a formação ideológica que se perpetuou no espaço transitado por Lima Barreto, evidenciou crenças da inferioridade do negro, "sem a ideia de que o negro seja "inferior" e necessariamente "subordinado"" ao "branco", a escravidão não seria possível num país cristão". (FERNANDES, 1972, p. 42). Essa forma de ser e pensar, condicionou o indivíduo africano ou de descendência africana a crer em sua debilidade; e o europeu conseguiu o respaldo da escravatura.

O racismo representa todas as forças antidemocráticas, formadas pela vantagem econômica, ou seja, tais forças implicam em ser bem nascido, ter recebido herança de pais ou parentes ricos etc. É uma maneira de querer ser melhor que o outro, e isso, sem esforços. Com o racismo forma-se monopólio de classes e/ou governos cujo poder é exercido apenas por indivíduos privilegiados. (ROSENFELD, 1993).

Diante disso, podemos dizer que a filiação discursiva de Lima Barreto se apoia, é claro, em várias FD's de diversos valores, mas a que trata da racialidade, em especial, foco desse trabalho, demonstra-se pela interdiscursividade de tal caráter.

Assim, tendo em vista que uma formação discursiva se estabelece por um sistema de relações linguísticas e interdiscursivas no qual acontecem os processos discursivos efetivos, as evidências intertextuais corroboram as diferenças entre os indivíduos. O período discriminatório vivido por Barreto demonstra, sem dúvida, a iniquidade da relação branco-negro.

Observaremos, a seguir o padrão discursivo e social de Fera ferida. O discurso telenovelístico é exteriorizado por meio de um trabalho coletivo, resultante de um conjunto de elementos que se articulam a partir do "padrão Globo de qualidade", sintagma que virou símbolo da TV Globo. Segundo Motter \& Mungioli (2007), a máxima da Rede globo não se traduz apenas por um slogan, a grade da programação, a execução e a produção de programas, além da organização da empresa, também obtiveram uma reestruturação, buscando tal excelência.

No entanto há quem conteste tal pensamento, como Eugênio Bucci $^{3}$ em seu artigo $O$ mau gosto e o desgosto, copyright Folha de $\mathrm{S}$. Paulo, 5/5/02:

\footnotetext{
${ }^{3}$ Bucci é Jornalista, tem o título de Doutor em Ciências da Comunicação, área de Jornalismo, pela Escola de Comunicações e Artes da USP.

${ }^{4}$ Disponível em: <http://www.observatoriodaimprensa.com.br/news/showNews/ asp080520029.htm>. Acesso em: 24 nov. 2013.
} 
Tenho insistido, e volto a insistir, que o padrão Globo de qualidade não era simplesmente uma escolha intencional dos gerentes, mas um padrão ideológico tornado possível pelo regime autoritário. Não é bem que a liderança da Globo se devesse ao seu autodenominado padrão de qualidade; era antes o contrário: o tal padrão é que só foi possível porque dispunha de condições prévias, o monopólio entre elas. O Estado autoritário distribuía as concessões como se fossem capitanias hereditárias, privilegiando certos grupos econômicos em detrimento de outros e inibindo a concorrência. Houve competência da Globo? (...) O que foi o padrão Globo de qualidade senão a face da integração nacional sob a ditadura? Claro que houve aí momentos de mal-estar, houve censura às novelas, houve arestas, mas nada disso foi definidor. O que definiu o padrão Globo de qualidade foi a necessidade imperativa de mostrar ao Brasil qual era a cara do Brasil. Era um Brasil de notícias governistas, de regionalismos de cartão-postal, de ufanismos futebolísticos e, por favor, sem negros nas novelas, sem evangélicos no horário nobre, sem excluídos desdentados no auditório. (...). O padrão Globo de qualidade era a expressão do bom gosto da classe média (bom gosto não é nada além do gosto médio da classe média). E não tinha concorrência, só por isso que reinava, mandão, pacífico e ordeiro. Ainda bem que ele já era. O que acabou não foi o padrão Globo, mas a sua sustentação histórica.

Percebe-se que a essência do poder incutido sobre o veículo televisivo consiste em seu estatuto de significação, que requer o controle do processo de significantes culturais por meio de uma entidade empresarial ou "tecnoburocrática" (SODRÉ, 1987, p. 10). Isto é, um moderno sistema tecnológico que rege indivíduos, economia etc.

Nesse campo de interação, defrontamos com o que Thompson (1995) denomina de instituições sociais, ou conjuntos exclusivos e possivelmente estáveis de recursos e regras que manifestam ao mesmo tempo com as relações sociais. A Rede Globo de Televisão, nesse sentido, pode ser caracterizada como uma organização que se constitui sob esse foco. Afinal, trata-se de uma empresa que apresenta certos tipos e quantidades de recursos constituídos a partir de regras próprias, normas de ação e com uma flexibilidade esquemática a qual administra os recursos e os sujeitos dentro 
dessa organização. Sob esse contexto, ainda, encontramos a possibilidade das relações hierarquizadas entre os indivíduos e/ou as posições ocupadas por esses (fato comum nas organizações Globo de Televisão). Esse processo interacional estruturante da Rede Globo apresenta aspectos os quais Thompson (1995, p. 198) nomeia de "assimetrias e diferenças relativamente estáveis em termos de distribuição de, e acesso a, recursos de vários tipos, poder, oportunidades e chances na vida."

Consoante a essas questões, a televisão torna-se um veículo eficaz para gerir um país, transformando-se em uma corporação que difunde de maneira maciça conhecimento, diversão, publicidade, informações etc. $\mathrm{Na}$ ordem dessa instituição prevalece a hegemonia e a ideologia capitalista. Através de tal aspecto, Sodré afirma que,

Os média vinculam estreitamente à organização monopolista do mercado - oligopólios e multinacionais controla os diferentes níveis de captação e receitas publicitárias e em ativos centros geradores de informações ideológicas dependentes do capitalismo ou do status quo. (SODRÉ, 1987, p. 32).

Destarte, o padrão estrutural da televisão, e claro, sua mediação pela telenovela se constitui sob o discurso advindo de um sistema econômico e social que se baseia na propriedade privada dos meios de produção, ou seja, assume uma FD capitalista.

No entanto, a conjuntura discursiva que nos interessa é da racialidade, e isso, só será exposto se houver algum interesse capitalista em jogo. A visibilidade no negro na televisão, e em particular na telenovela, é ínfima, tal fato corrobora-se através do estudo de Araújo. Observemos:

Examinamos 512 telenovelas e a constatação foi chocante:

Identificamos que:

- em um terço das telenovelas produzidas até 1997 não havia nenhum personagem afrodescendente.

- Apenas em outro terço o número de atores negros contratados conseguiu ultrapassar levemente a marca de $10 \%$ do total do elenco. 
- E, 90\% dos personagens criados representavam a subalternidade do negro na sociedade brasileira. Ou seja, traziam os negros em estereótipos de si mesmos.

(...) somente as duas últimas décadas do século XX, os anos 80 e 90, um período de ouro da telenovela, marcado por autores progressistas como Dias Gomes:

- de 98 novelas produzidas pela Rede Globo não foi encontrado nenhum personagem afro-descendente em 28 delas.

- Apenas em 29 telenovelas o número de atores negros contratados conseguiu ultrapassar a marca de dez por cento do total do elenco.

- E em nenhuma delas o total de negros e pardos chegou a ser metade, ou mesmo $40 \%$ de todo o elenco. (ARAÚJO, 2012, p. 02).

A consequência desse discurso se traduz pela negação do negro brasileiro, emergindo a FD racial, alimentada pelo discurso dominante, acessível apenas pela elite simbólica (de raça branca) e colaboradora da difusão desigual entre os seres.

Nessa perspectiva, conjecturamos que a filiação discursiva de Aguinaldo Silva e coautores, também, situa-se no âmbito de uma FD capitalista. Observemos o trecho abaixo extraído do blog de Silva que nos possibilita pensar tal hipótese.

Quando você adapta um livro para uma novela, minissérie ou filme de longa-metragem, a liberdade de criação é decisiva, assim como deve ser absoluta a fidelidade do adaptador à essência da obra original. Lembra daquela frase? Quem ama não mata? Eu diria: quem adapta não trai. Aguinaldo diz que só não fez mais cinema porque em comparação com o que se paga na TV é muito pouco. ${ }^{5}$

Parece-nos, assim, que a filiação discursiva dos autores têm a capacidade de reproduzir a veleidade racial brasileira, legitimando o mito

\footnotetext{
${ }^{5}$ Cfe. $<$ http://asdigital.tv.br/portal/?p=7465>. Acesso em: 15 jan. 2014.
} 
da democracia racial e o posicionamento imposto pela classe dirigente, que preza o domínio de vida capitalista.

A partir de tais constatações, identificamos posições singulares que delimitam o que se pode e o que se deve dizer acerca do Outro negro/ mulato/pardo/afrodescendente. A FD de caráter antirracial trazida pelo posicionamento de Lima Barreto, assim como, a FD capitalista vinculada à televisão e o seu gênero telenovela se articulam como um complexo dominante que pode orientar para outras FD's, e nesse caso, segundo o recorte desse trabalho, pode direcionar-se a uma FD racial, alimentando-a. Aquela por seu caráter contraditório, como forma de ratificar a existência racial, e esta pela possibilidade da associação do discurso capitalista que se aproveita de seu modo dominante para corroborar as práticas raciais a partir das relações de exploração.

Sob tais circunstâncias, postulamos algumas FDs que julgamos recorrentes nos nossos processos sociais e sobre as quais pretendemos desenvolver as análises no âmbito das enunciações ficcionais.

- FD1: superioridade racial (não apenas de reconhecimento do lugar de superioridade, mas também de atribuição do lugar de inferioridade ao outro, e/ou autoafirmação enquanto um ser social);

- FD1.1: discriminação de cor (o reconhecimento e a atribuição de papeis subalternos a pessoas de cor negra e/ou suas variantes cromáticas);

- FD1.2: discriminação sexual (reconhecimento e atribuição de papeis secundários e subalternos geralmente a mulheres de cor negra);

- FD2: inferioridade racial (é a partir dela que discursos de submissão, de conformismo, de aceitação de papeis subalternos difundidos numa sociedade);

A noção de FD segundo a base proposta por Pêcheux se realiza sob as regularidades particulares de posições de classes definidas em função de embates ideológicos constitutivos de uma situação histórica, política e social. A partir desse viés, então, conjecturamos as FD's raciais, tendo em vista as várias possibilidades interpretativas acerca da racialidade que circundam o meio social brasileiro. Logo, pressupomos que algumas das 
FDs elencadas podem identificar melhor o posicionamento discursivo dos sujeitos ficcionais estabelecidos por esse estudo.

Assim, observemos na próxima seção a partir de certos trechos das narrativas Clara dos Anjos e Fera ferida as possibilidades de FD's que circunscrevem tais discursos.

\section{A microestruturação enunciativa da Clara barretiana em contraposição a criação de Aguinaldo Silva}

O lugar da constituição do sentido é a formação discursiva, isso implica defini-la em função de sua dependência constitutiva do "todo complexo com dominante", ou seja, do interdiscurso (PÊCHEUX, 1997, p. 162). Desse espaço apreende-se o efeito de pré-construído "semprejá-aí da interpelação ideológica" e a articulação constituída pelo "sujeito em relação com o sentido", que são evocados através do processo da interdiscursividade (PÊCHEUX, 1997, p. 164). O pré-construído faz alusão a determinadas certezas manifestadas pelo sujeito através de sua enunciação, isto é, "o que cada um sabe e simultaneamente o que cada um pode ver”. (BRANDÃO, 2004, p. 49).

Diante dessa perspectiva, observaremos, nesse momento, a formação discursiva que envolve a personagem Clara dos Anjos, inscrita no romance de Lima Barreto, tendo em vista o lugar assumido por esse sujeito ficcional em um dado momento histórico e social da narrativa barretiana.

A circunstância histórica do contexto expresso por Clara nos remete aos idos de 1900. A personagem se insere em uma classe social baixa, um estado de pobreza, e ainda, apresenta a condição física de ser mulata. Sob esse espaço discursivo apresentaremos, a seguir, alguns recortes, visando demonstrar o posicionamento socioinstitucional e ideológico conferido a Clara, como se pode observar abaixo:

\begin{tabular}{|c|c|}
\hline Narrador: & $\begin{array}{l}\text { Na sua vida, tão agitada e tão variada, ele sempre observou a atmosfera } \\
\text { de corrupção que cerca as raparigas do nascimento e da cor de sua } \\
\text { afilhada; e também o mau conceito em que se têm as suas virtudes de } \\
\text { mulher. } A \text { priori, estão condenadas; e tudo e todos pareciam condenar os } \\
\text { seus esforços e os dos seus para elevar a sua condição moral e social. }\end{array}$ \\
\hline
\end{tabular}

(BARRETO, 1998, p. 42 - destaques meus) 
Nessa passagem o narrador revela o pensamento de Marramaque em relação às moças de cor, como é o caso de Clara, e nela estão contidos os primeiros aspectos da FD1 que assinala aquilo que se pode dizer em relação a esses indivíduos como se pode notar pelos grifos assinalados acima. A FD1.1, surge assinalando o teor discricionário sobre a mulher negra - " (...) o mau conceito em que se têm as suas virtudes de mulher (...)"(BARRETO, 1988, p. 42) . Por fim, a sentença final desse episódio: "A priori, estão condenadas; e tudo e todos pareciam condenar os seus esforços (...)" (BARRETO, 1988, p. 42) revela-nos o caráter determinista desenhado pela FD1.

$\mathrm{O}$ inusitado do tratamento de superioridade racial configurado acima, se pauta pela reflexão advinda de Marramaque, um mulato, padrinho da jovem Clara; demonstrando o assujeitamento e/ ou a interpelação sofrida por esse indivíduo perante um discurso discriminatório presentificado por uma formação ideológica racializante, que ele reproduz, mesmo sendo um representante da classe que sofre o preconceito.

Marramaque viveu no meio de "rodas de gente fina" (BARRETO, 1988, p. 40); apesar de pouca instrução e apresentando uma saúde debilitada, esse personagem presenciou um período de:

Plena escravatura, se bem que nos fins, mas a antiga Província do Rio de Janeiro era próspera e rica, com as suas rumorosas fazendas de café, que a escravaria negra povoava e penava sob os açoites e no suplício do tronco. (BARRETO, 1998, p. 36).

Diante disso, percebe-se que Marramaque, enquanto "sujeito de cor", reproduz a ideologia da supremacia branca. Essa possibilidade enunciativa, segundo Fanon, corrobora-se à medida que entendemos que o negro se autoescraviza, após ter sofrido como escravo do branco. "O preto é na máxima acepção do termo, uma vítima da civilização branca." (FANON, 2008, p. 162). Sendo assim, ele não tem seu próprio lugar e discurso, reproduz o padrão social em que vive.

$\hat{\mathbf{E}}$ interessante pensar, também, que esse contexto social expressa a riqueza brasileira que se constrói sobre o trabalho escravo, o que pressupõe uma ideologia racista, se constituindo a partir de uma prática social que tem como base a dissimetria entre a relação branconegro, perpetuado sob a desigualdade da estrutura social. 
Clara, no próximo excerto, parece começar a entender sua posição na sociedade revelada pela narrativa barretiana:

\begin{tabular}{l|l}
\hline Narrador: & $\begin{array}{l}\text { Uma dúvida lhe veio; ele era branco; e ela, mulata. Mas que tinha isso? } \\
\text { Havia tantos casos... Lembra-se de alguns... E ela estava tão convencida } \\
\text { de haver uma paixão sincera no valdevinos, que, ao fazer esse inquérito, já } \\
\text { recolhida, ofegava, suspirava, chorava; e os seus seios duros quase estouravam } \\
\text { de virgindade e ansiedade de amar. }\end{array}$ \\
\hline
\end{tabular}

(BARRETO, 1998, p. 56 - destaques meus)

No entanto, o entendimento revelado pela jovem Clara está longe de representar uma ruptura da FD1, quando muito reproduz a extensão daquilo que é dito (ou imaginado) acerca do discurso racial: "Uma dúvida lhe veio: ele era branco; e ela, mulata (...)" (BARRETO, 1998, p. 56). Há nesse contexto, certo conformismo diante da incerteza colocada pelo posicionamento da cor do sujeito, que se traduz pelo enunciado: “(...) já recolhida, ofegava, suspirava, chorava (...)" (BARRETO, 1998, p. 56).

Nesse sentido, Memmi nos lembra que o sujeito acaba por reproduzir os padrões de dominação em que vive, traduzidos aqui, em termos das FDs supracitadas, já que é através delas que os sujeitos exteriorizam as marcas profundas da discriminação. Nesse caso, Clara, ao tentar ignorar a separação social estabelecida pela diferença de cor entre ela e Cassi Jones, se convence da superioridade branca e busca viver dentro dos padrões dessa sociedade, imbuída pela força de FD2, como ratificado nas palavras de Memmi:

O colonizado se perde no "outro", se aliena. Tentará, pois, de acordo com a lógica desse movimento, levar a alienação às últimas consequências, tornando-se ele próprio um colonialista, casando-se entre os representantes da metrópole, por exemplo. (MEMMI, 1977, p. 08 destaque do autor).

Clara, ao dizer que “(...) não somos nada nessa vida!” (BARRETO, 1998 , p. 133), revela que suas condições econômica e de cor eram algo determinante na sociedade vigente da época. Esse fato reforça a ideia da imobilidade social de Clara, dado que se torna preponderante na construção de um modelo comportamental de inferioridade, de conformismo, por parte dessa personagem, o que vem reforçar a FD2. 
A partir desses apontamentos, percebemos que os atos enunciativos que circunscrevem Clara adquirem uma estabilidade referencial a partir de certa conjuntura histórica e social, e se apoiam em saberes instituídos e legitimados no circuito social brasileiro, revelados pelas posições discriminatórias em relação ao Outro (negro/mulato/afrodescendente).

Um problema que é bastante evidente no Brasil, (...) é das relações entre negros puros e mulatos. Muitas vezes o negro se ressente do que os mulatos têm de sangue branco, vendo-os, pelo menos em parte, como membros da raça que oprimiu o negro. Um outro sentimento (...) é o da vergonha por parte do negro, reconhecendo que os primeiros mulatos foram fruto de violentações dos brancos contra as mulheres escravas, geralmente à força ou sem consentimento delas. (...) o mulato permanece como símbolo de traição forçada imposta ao macho africano. (...) Seu sangue negro o impede de ascender a uma posição de igualdade social com brancos, enquanto seu sangue branco o separa dos negros, o que muitas vezes o infelicita. (RABASSA, 1965, p. 440).

O contexto social brasileiro atribui um caráter depreciativo ao ser negro(a) e/ou mulato(a), dado que corrobora para a violência simbólica que envolve esses sujeitos.

Já, a Clara dos Anjos de Fera ferida, representada pela atriz Érica Rosa, nessa trama televisiva, vive em um colégio de freiras até seus dezesseis anos. Ela volta para a cidade de Tubiacanga para assumir seu legado: ser a nova rainha da irmandade, posto passado de geração a geração (Engrácia, mãe dessa jovem passaria seu governo de rainha à filha).

Assim, a partir de determinadas enunciações tomaremos o padrão racializante que envolve a personagem Clara da trama telenovelística como é possível verificar no excerto abaixo:

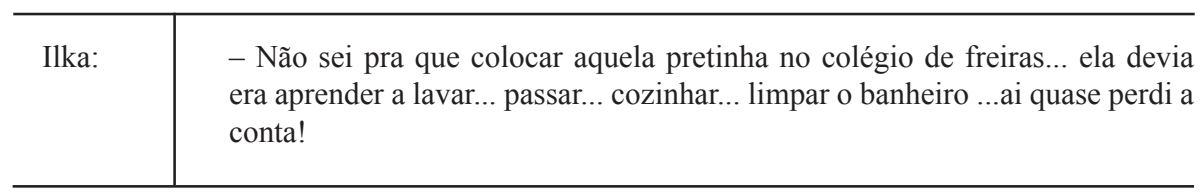

(SILVA, LINHARES e MORETZSOHN, 1993. Transcrição minha - destaques meus) 
Aqui a personagem Ilka se apresenta como uma mulher branca, da sociedade de Tubiacanga e cunhada do prefeito dessa cidade, Demóstenes. Seu discurso se realiza por meio uma conversa informal com Joaquim dos Anjos, pai de Clara. Ela pergunta a Joaquim sobre a filha, mas sem que ele perceba, essa personagem expõe o que pensa a respeito de Clara. A opinião de Ilka nos remete a FD1.1, além da FD1 que determina a exterioridade preconceituosa dessa personagem, assim como assegura o seu lugar de soberania social. Ao pronunciar que Clara devia era "lavar... passar... cozinhar" (SILVA, LINHARES e MORETZSOHN, 1993), Ilka atribui, através desses significantes, que à força do trabalho doméstico é algo imanente ao destino do negro.

A condição social e de cor da jovem Clara e de sua mãe acabam por colocarem-nas numa situação de desvantagem perante essa sociedade, manifestando a intolerância de Salustiana: "Não me diga que você andou se metendo novamente com essas mocinhas de cor... (SILVA, LINHARES e MORETZSOHN, 1993), ocorrência que assinala a FD1.1, fato decorrente da interação entre Salustiana mãe de Cassi Jones, amante de Clara e Engrácia a progenitora de Clara dos Anjos. A FD1.2, também, condiciona o modo de ser de Salustiana na a fala: “(...) essas meninas se apegam.... também não é pra menos... chegam a pensar que são gente!! Quando um rapaz assim de boa família... bonito... papa fina, dá o prazer a elas de dividir um pouco da sua intimidade..." (SILVA, LINHARES e MORETZSOHN, 1993). Nessa fala a personagem manifesta o preconceito em relação aos relacionamentos afetivos entre etnias diferentes.

Para a maioria dos brancos o negro representa o instinto sexual (não educado). O preto encarna a potência genital acima da moral e das interdições. (...) a realidade desmente todas essas crenças. Mas tudo isso se acha no plano do imaginário (...). (FANON, 2008, p. 152).

Nota-se, que a mulata é reduzida ao corpóreo e à sexualidade que pode oferecer. Essa herança advém do processo escravagista brasileiro. Sobre isso, Freyre explica que: “(...) a animalidade dos negros, essa falta de freio nos instintos, essa desbragada prostituição dentro de casa, animavam-na os senhores brancos." (FREYRE, 2002, p. 402).

A construção discursiva de Aguinaldo Silva e Linhares e Moretzsohn (1993), mesmo sendo contemporânea, ainda carrega consigo 
os estigmas sociais da discriminação. As representações em torno de Clara corroboram para esse dado e se manifestam sob a FD2.

Existe, nesse contexto, uma ideologia racial presentificando a questão apontada, como vimos nos discursos racistas de Ilka e Salustiana, representações que se traduzem pela FD1. Nesse sentido, apreende-se que "em qualquer dos disfarces, os negros desfrutam de uma posição subordinada no sistema dualista que reproduz a dominação da brancura". (GILROY, 2001, p. 109). A mãe de Clara, ao constatar que a filha envolveu-se com Cassi, chega à seguinte conclusão: “- Hum! Ser alguma coisa! Ser alguém! É Joaquim eu acabei de descobrir que a gente não vale nada nessa vida!" (SILVA, LINHARES e MORETZSOHN, 1993). Assim, a proposição em destaque exterioriza a ocorrência da FD2 nesse âmbito.

Como se pode verificar, a personagem Clara vive em uma sociedade branca, que dita as regras, as quais estigmatizam as pessoas de cor. Logo, a identidade discursiva dessa jovem se constrói na relação com o Outro branco, que estabelece o lugar dela perante a sociedade de Tubiacanga, o que nos leva a presumir que tal personagem se assume por um FD de inferioridade racial, isto é, a FD2.

Percebe-se que Fera ferida, mesmo sendo uma construção dos anos noventa, ainda tem como base o discurso escravagista como pilar para a racialização apresentada. Clara se insere em um contexto discriminante, mas que se faz por uma ótica restrita. Nessa telenovela, o preconceito emerge através de um contexto particular, no qual se inserem apenas alguns personagens, como Ilka, Salustiana, Rubra Rosa (esposa de Numa), o delegado da cidade (que tem um caso com Salustiana), enfim, um pequeno grupo de pessoas. Não há maiores preocupações voltadas para o debate racial.

Contudo, percebe-se que a modernidade, aos poucos, começa a fazer parte do contexto vivido pela jovem Clara. Notemos a fala de seu pai, Joaquim no enunciado seguinte: "Claro, Engrácia. É o que ela quer! A Clara sempre foi muito estudiosa, muito esforçada... ela vai se formar, ser professora... fazer uma faculdade, ser até doutora, Engrácia!" (SILVA, LINHARES e MORETZSOHN, 1993). Essa Clara, de Fera ferida, diferente da Clara, de Lima Barreto, que não tem outra perspectiva social a não ser a desonra, pode recorrer ao estudo e tentar modificar seu padrão de vida inferiorizante. 
A Clara de Lima Barreto reproduz a racialização por meio do coletivo. Toda a obra apresenta ou conduz para uma perspectiva coletiva acerca de raça. Diferente da telenovela, que concentra essa problemática em apenas um núcleo. Nesse sentido, o modo de produção social inscrito nesse âmbito demonstra a subalternidade do negro, conforme nos explica Muniz Sodré:

[a] elite branca fazia o trânsito histórico do racismo de dominação para o de exclusão: o homem concreto, o povo, seria socialmente discriminado (...) a ideia de nação confundia-se com a de uma comunidade baseada em laços de sangue ou território. Mais tarde no século dezenove, a comunidade "sanguínea" tornou-se comunidade de "raça", isto é, uma unidade política garantida tanto pelo ordenamento estatal quanto pela ideia de uma diferença biológica a nível humano. A manipulação de diferenças servia a propósitos coloniais: manter o outro, o colonizado, em posições subalternas. (SODRÉ, 1999, p. 79 - destaques do autor).

O coletivo apresentado pela novela Fera ferida mascara a racialidade. O preconceito surge em posições individuais, que fantasiam um espaço de superioridade em relação aos pobres e negros presentes nessa narrativa.

A contemporaneidade da narrativa de Aguinaldo Silva e coautores talvez pudesse repensar a história da Clara barretiana, mas não o faz. Reproduz a situação de Clara com brandura, própria de sua função social, enquanto gênero de entretenimento. E assim, diverge da literatura barretiana em seu tom de transformação, reflexão e/ou a discussão acerca da racialidade brasileira.

Outro aspecto em desarmonia com obra de Barreto é a conformidade da situação discriminante da jovem Clara sob o ponto de vista de Engrácia, ao dizer que não se vale nada nessa vida, diferente do acontece na obra de Barreto, pois nela a perspectiva do não ser nada na vida já parte da própria Clara.

No Brasil, como não se toca mais publicamente na "questão nacional" (levantada em 1822, 1888, e 1930), a temática identitária foi abandonada pelas elites dirigentes e retomada por "comunidades" setoriais (negros, índios, 
mulheres, homossexuais etc.). Na imprensa, apenas eventualmente o problema da discriminação é aflorado, mas sem compromisso de causa, daí as acusações de conivência na reprodução de formas discriminatórias. (SODRÉ, 1999, p.134-135 - destaques do autor).

Nesse sentido, a telenovela também não está preocupada em discutir a racialidade, apenas reproduz o social como ele sempre foi retratado: o branco em lugar de poder e de dominação e o negro em seu estado de dominado.

Assim, as proposições analisadas nos direcionam, em ambas as narrativas, para FD2 de inferioridade racial, assim como, aquela que denota a superioridade racial, FD1. Os discursos de aceitação da subalternidade e submissão que são impostos à personagem Clara, tanto na construção de Barreto quanto na de Aguinaldo Silva e outros se corroboram pela FD2, enquanto a hegemonia branca e a discriminação de cor e sexual se exprimem pela FD1, FD1.1 e FD 1.2, que atribuem ao "sujeito de cor" um não-lugar social, dado que o mantém à margem e o exclui perante uma sociedade de preceitos racistas.

\section{Considerações finais}

Sob tais considerações, Lima Barreto parece-nos um autor que deseja a fusão do real com a ficção e, em função disso, cria uma obra ficcional cuja história não permite o afastamento da realidade. Nesse âmbito surgem as narrativas de acontecimentos e fatos que demonstram a situação das famílias cariocas no início do século XX, atentando para a maneira de agir de alguns grupos sociais que contribuiriam direta ou indiretamente na formação da nova sociedade que estava por vir. Sendo assim, o autor situa bem sua escrita a partir da opção que faz por relatar a vida dos pobres, negros, mulatos etc. A hipocrisia social e racial, então, vem à tona pela navalha da escritura realista barretiana.

Nesse sentido, a obra de Barreto ressignifica a óptica racial por meio da criação de "uma literatura social politicamente militante, voltada para a urgência do cotidiano em mudança e ao mesmo tempo inspirada na redenção do homem e na defesa do trabalhador oprimido pelas distorções sociais". (PRADO, 1980, p. 13). De forma divergente, a narrativa de Fera Ferida mostrará, em sua trama, a desconstrução dos discursos produzidos sobre o negro, perspectiva que distorce a racialidade 
e, consequentemente, demanda uma nova ordem, como a criação de leis que se interpõem de forma a rever a questão racial.

\section{Referências}

ALTHUSSER, L. Aparelhos ideológicos de estado: nota sobre os aparelhos ideológicos de estado (AIE). Tradução Walter José Evangelista e Maria Laura Viveiros de Castro. Rio de Janeiro: Graal, 1983.

ARAUJO, Joel Zito. Manifestação proferida na audiência pública da comissão de educação e cultura - CEC DA CÂMERA DOS DEPUTADOS FEDERAIS, 2012. Disponível em: <http://ppaberlin. com/2012/08/30/manifestacao-proferida-na-audiencia-publica-dacomissao-de-educacao-e-cultura-cec-da-camera-dos-deputadosfederais/> Acesso em: 12 out. 2013.

BARRETO, Lima. Bagatelas. São Paulo: Brasiliense, 1956.

BARRETO, Lima. Clara dos Anjos. 11. ed. São Paulo: Ática, 1998.

BOSI, Alfredo. Formações ideológicas na cultura brasileira. Estudos avançados, v. 9, n. 25, p. 275-293, 1995.

BOSI, Alfredo História Concisa da Literatura Brasileira. São Paulo: Cultrix, 1970.

BRANDÃO, Helena H. Nagamine. Introdução à análise do discurso. Campinas: Editora da Unicamp, 2004.

COURTINE, J.J.; MARANDIN, J. M. Quel objet pour l'analise du discourse. Lille: Press Universitaires de Lille, 1981.

FANON, Frantz. Peles negras, máscaras brancas. Tradução de Renato da Silveira. Salvador: Edufba, 2008.

FERNANDES, Florestan. O negro no mundo dos brancos. São Paulo: Difusão Europeia do livro, 1972.

FREYRE, G. Casa grande \& senzala: formação da família brasileira sob o regime da economia patriarcal. Edição crítica de Guillermo Giucci, Enrique Larreta, Edson Fonseca. Paris: Allca XX, 2002. (Coleção Archivos). 
GILROY, P. O Atlântico negro: modernidade e dupla consciência. São Paulo/Rio de Janeiro. Universidade Cândido Mendes - Centro de Estudos Afro-Asiáticos. 2001.

HOLANDA, Sérgio Buarque de. Raízes do Brasil. 26. ed. São Paulo: Companhia das Letras, 1995.

LINS, Osman. Lima Barreto e o espaço romanesco. São Paulo: Ática, 1976.

MOTTER, Maria Lourdes; MUNGIOLI, Maria Cristina Palma. Gênero teledramatúrgico: entre a imposição e a criatividade - um breve retrospecto. Revista USP, São Paulo, n. 76, p. 157-166, 2007.

ORLANDI, Eni P. Análise de discurso. In: ORLANDI, Eni P.; LAGAZZIRODRIGUES, Suzy. (Org.) Introdução às ciências da linguagem discurso e textualidade. Campinas: Pontes Editores, 2010. p. 11-33.

RABASSA, Gregory. O negro na ficção brasileira: meio século de história literária. Rio de Janeiro: Tempo Brasileiro, 1965.

ROSENFELD, Anatol. Texto, contexto II. São Paulo: Perspectiva / Ed. da Universidade de São Paulo, 1993.

PRADO, Antonio Arnoni. Lima Barreto Personagem de João Antônio. Novos Estudos, v. 54, n. 3, p. 73-84, jul.1999.

PRADO, Antonio Arnoni. Literatura comentada: Lima Barreto. São Paulo: Abril Educação, 1980.

PÊCHEUX, Michel. Semântica e discurso: uma crítica à afirmação do óbvio. Trad. Eni Pulcinelli Orlandi et al. São Paulo: Unicamp, 1997.

SODRÉ, Muniz. Televisão e psicanálise. São Paulo: Ática, 1987. (Série Princípios)

THOMPSON, John B. Ideologia cultura moderna: teoria social crítica na era dos meios de comunicação de massa. Petrópolis: Vozes, 1995. 